creep may be almost as important as the thermal effects. One group of papers presented in this session reviewed the incidence of shrinkage cracking in different types of dams. H. A. Hupner, for example, reported on some twenty-nine concrete dams in France of which twelve showed no sign of cracking. The creep of concrete, and the redistribution of stress to which it leads, is of first importance in determining the behaviour of concrete that is undergoing volume charge, and several of the papers dealt with this subject from theoretical or experimental points of view.

The design of concrete mixes for dam construction and the minimum permissible cement content also came under review. Following the unfortunate experience of the Scandinavian countries with lean concrete dams built twenty years or more ago, the use of richer mixes became general. A reverse tendency is now to be found in the practice in the United States, where the cement content of the concrete has been progressively lowered over the past decade. The factor determining the minimum cement content, at least as far as gravity dams are concerned, is the permeability of the concrete, rather than its strength, and here the nature of the im pounded waters becomes important. Deterioration of dams in Scandinavia has been associated with a very low hardness of the water and, in consequence, a marked leaching action on the set cement where it permeated through the concrete. With harder waters the initial permeability may decrease rather than increase with time, and it is to be noted that most of the waters stored by dams in the United States are hard. It was, nevertheless, evident that there is still a marked divergence of opinion between European and American designers on this subject. Though Portland cement is the main cementing material used in the construction of concrete dams, the use of pozzolanic cements and of cements containing granulated blast-furnace slag is increasing. These offer some advantage from the point of view of heat evolution during setting and watertightness. In India, surkhi, a powdered burnt clay, has been used as a pozzolanic admixture to lime mortars from the earliest times, and, more recently, as an admixture to Portland cement mortars. A number of papers contributed by Indian authors dealt with this material.

The last technical session of the Congress was concerned with the silting of reservoirs and related problems. The rate of sedimentation in reservoirs is of much economic importance, because of the reduction in storage capacity which ensues over the years. The papers presented dealt with the causes of erosion, the mechanism of the transport of solids by water, and the factors determining the rate of deposition. The great variation in the amount of solids carried by rivers was illustrated by figures given for the Missouri, where, at times of low water, the average percentage of materials carried in suspension seldom exceeds 0.02 per cent by weight, though at the time of high flood it rises to 1 per cent. General practice in the past has been to provide a capacity in reservoirs which lnaves a margin for silting sufficient for a considerable period of years. Methods of combating silting are now attracting much more attention, and ixtend, for example, to control, which is so much needed for quite other reasons, over the soil erosion.

Following the Congress, a tour starting in Northern India and later proceeding across the Deccan Plateau to Southern India had been arranged. In the course of this, members of the Congress were able to see constructional work in progress on dams and irriga. tion projects, as well as completed structures. One notable point of call was the Bhakra project on the Sutlej River. At a point where this river breaks through the last foothills of the Himalayas, a narrow gorge is to be dammed with a concrete dam $680 \mathrm{ft}$. in height. Two 50-ft. diameter diversion tunnels, which will carry the river round the dam site during construction, were being driven at the time of the visit. The hydraulic laboratories at Pathankot and Poona and other engineering laboratories were also visited. The tour not only gave the delegates an opportunity of seeing the many large-scale civil engineering works now in progress in India, but also a cross-section of the Indian countryside. A final closing session of the three international meetings was held in Mysore on February 1.

Throughout the meetings at Delhi and the sub. sequent tour the members were afforded widespread hospitality and help from their Indian hosts. The combination of the large meetings in Delhi, the International Engineering Exhibition, and the tour made a memorable occasion in the history of engineering in India.

F. M. LEA

\section{PURE FOOD LAWS IN GREAT BRITAIN}

TN January 1851 the Lancet opened a campaign against the widespread practice of adulterating food, and the campaign culminated in the passage in 1860 of the first Act of Parliament designed to control the quality of the food offered for sale to the general public. It is interesting to follow the century of progress that has been made since those times, and Dr. G. W. Monier-Williams gave an interesting review of the development of legislation to control the purity of food in a paper which he read at the opening of a symposium on "Nutrition and the Pure Food Laws" held by the Nutrition Society on March 3.

Both the first Act of 1860 and the one succeeding it in 1872 rapidly became dead letters, but the third Act passed in 1878 survived in its genoral form until 1938, when some of its provisions were incorporated in the Food and Drugs Act that is in force to-day. Dr. Monier-Williams laid emphasis upon the debt we owe to the energy and enthusiasm of some of the public analysts appointed under the early Acts. Their work, often carried on in the face of bitter opposition from trade interests, laid the foundation for much of the present-day legislation.

Prosecutions for the deliberate adulteration of food have fallen steadily over the years until there is now left little but the very small hard core of offenders in the retail milk trade who seem unable to resist the occasional temptation to add water to their wares. Although the early Acts stressed the desirability of laying down food standards, the powers necessary to do this were not granted until the passage of the Act of 1938. The task of carrying out the provisions of this Act has passed from the Ministry of Health to the Ministry of Food.

The next speaker, C. A. Adams (Ministry of Food), outlined the work his department is doing in regulating the standard of food retailed to the public. One most important aspect is the control of labelling, and the Ministry has organized an advice bureau to assist, quite informally, manufacturers in the design- 
ing of labels to comply with the provisions of the Act. It has approved more than sixty thousand such labels and in this way has probably prevented much litigation. The labels of all prepacked food must contain a list of the ingredients with the main ingredient named first. It must be free from misleading claims about the value or properties of the food. If a content of vitamin is claimed, the exact amount must be stated in international units.

Mr. Adams contrasted the great interest taken in the quality of food by both the Government and people of the United States with the indifference shown in Great Britain. He pleaded for a better education of the public in these matters so that they would come to demand cleaner food of the highest possible standard and so do much to make the work of the Ministry easier. He described the procedure adopted for setting up a standard for any particular food. In principle, it is similar to that used by the Food and Drug Administration of the United States, though it is not carried out on anything like the same scale. Sub-committees are at work at the present time trying to lay down limits for metallic contaminants and considering the use of new preservatives and other chemicals likely to prove popular, especially with the baking trade.

A revealing comparison between the legal control of the quality of the food sold for consumption by farm animals and the laws affecting the food of the human population was drawn by J. King (Government Chemical Laboratory). In his opinion the Fertilizer and Feeding Stuffs Act of 1926 was an extremely enlightened piece of legislation pointing to the influence and ability of those who had the care of agricultural livestock at heart. Not only are exact standards laid down, but also the analytical methods to be used are stipulated in regulations under the Act. In the case of fraud or adulteration the Ministry of Agriculture can instigate criminal proceedings against the vendor, and the farmer can attack him in the civil court. Mr. King pointed out how difficult it is to lay down standards for a food fed to so many widely differing species; thus the husk or fibre content of a meal may be of no value to pouitry, whereas more than sixty per cent may be available as carbohydrate to the species that can digest the cellulose. He went on to mention some of the difficulties in devising laboratory methods for such apparently simple procedures as the determination of water content. New methods suitable for materials containing volatile ingredients or those that are readily decomposed by heat are still being put forward. Since the advent of crystalline amino-acids, the venerable Kjeldahl method has been the subject of much closer examination, and its behaviour with different catalysts has been the subject of interesting study.

Dr. J. M. Barnes (Medical Research Council Toxicology Research Unit) named a few of the materials found in food to-day and outlined the experimental work that has been done in an attempt to assess their toxicity. He emphasized the difficulty of interpreting the results of experiments on animals in terms applicable to man. Any chemical added to food must be harmless to both young and old, and sick and healthy. The problem of the hypersensitive individual cannot be overlooked. The possibility that a new synthetic chemical may have carcinogenic properties must be remembered.

In general, a case against the use of most substances recommended for deliberate addition to food does not rest on evidence of their toxicity as provided by laboratory experiments. Such consideration does not necessarily apply to more active materials, such as insecticides, that might find their way into food as the result of modern practices in the control of infestation, etc.

Dr. J. B. M. Coppock (Baking Industries Research Station) said that he would divide chemicals found in food into three categories : additives, processing aids and hygiene aids. As an example of each he mentioned glyceryl monostearate as an anti-staling agent for addition to bread, the use of silicones as pan glazes in baking, and the quaternary ammonium cationic detergents used for cleaning vessels employed in food production.

He stressed the need for more information on the toxic properties of all such materials, and mentioned that the ideal solution might be the setting up of a large institute where such testing might be carried out. $\mathrm{He}$ realized that, under prevailing economic conditions, this would be impracticuble for many years. $\mathrm{He}$ thought that with existing scientific resources all substances that might be added deliberately or incidentally to food could be examined in the following way. An initial screening for acute toxicity would exclude all chemicals with obviously harmful properties, and for those passing this test a full investigation of their functional value should next be made. For purposes of comparison it is necessary to devise as many quantitative tests as possible. It is Dr. Coppock's opinion that the number of materials found to satisfy the first test and then shown to be significantly superior in function to materials already in use for the same purpose would be very small. At this point there is an urgent need for an advisory committee with powers to examine all the available evidence, and then pronounce whether or not a case has been made out for a new material to be recommended for use after it has been put through a thorough examination for absence of long-term toxic effects. Dr. Coppock believes that the work of examining those materials ever likely to be deemed worthy of such detailed investigation would be within the limits of existing resources in university or other laboratories.

Dr. Coppock concluded by emphasizing the need for a permitted list of materials that could be added to food. This point was taken up during the discussion, and the position in Great Britain was contrasted with other countries where such permitted lists are the basis of control over the addition of chemicals to food. In Britain only those substances that may not be added to food are listed.

\section{OBITUARIES}

\section{Dr. G. M. Smith}

ANGLO-AMERICAN co-operation in medical research has suffered a severe loss in the death, which occurred on February 26, of Dr. G. M. Smith, of Pine Orchard, Connecticut. George Milton Smith graduated A.B. (Yale) in 1901 and M.D. (Columbia) in 1905, and later became associate and associate professor of pathology in Washington University (St. Louis), where he worked during 1910-34. He then returned to Yale on appointment as medical director of the Anna Fuller Fund, which post he still retained at the time of his death. While in Yale he also acted as research associate in anatomy; of later years his 